\title{
Through the Google Glass: Configurations of Attention in the Age of Digital Media
}

EVA ZEKANY, CENTRAL EUROPEAN UNIVERSITY

\begin{abstract}
In this paper, I discuss a recently documented case of media addiction, that of the first person ever to be treated for internet addiction induced by the use of Google Glass. Taking this case as a starting point, I draw together strands from new materialism and N. Katherine Hayles' work on attention in order to argue that the contemporary debate on media addiction translates into a reconfiguration of attention as an embodied, embedded and finite resource. Google Glass thus occupies a precarious and paradoxical place in today's attention economy: as both a gateway to a technical wonderland, and as a corrosive agent that disrupts the proper workings of the social.
\end{abstract}

\section{KEYWORDS}

Attention; Internet Addiction; Materiality; Media Theory 


\section{Introduction}

There never seems to be a shortage of scurrilous news surrounding various pieces of new technology - from cell phone usage on the male reproductive system, to the destructive influence of internet pornography on traditional courtship, of online games on the cognitive abilities of children. The general conclusion seems to be that new technologies are a doubleedged sword, ready to cut us off from a retrospectively idyllic traditional lifestyle, despite heralding an enlightened, care-free high-tech future. This type of hand-wringing is by no means a recent phenomenon. Media historian John Durham Peters, in his comprehensive history of the idea of communication (1999) describes how discourses surrounding 'older' media forms reveal an unease about disembodiment (in the case of the telegraph), mass mind control and manipulation (the radio, print media), and emotional desensitization (the television). Pushed to its logical limits, the discourse on the potential treachery of media technologies, especially communications media, seems to be a discourse on the fear of losing something that characterizes the human as intrinsically human - be it social bonds, higher cognitive functions, or a sense of mastery over of technological tools.

Fuller and Goffey, media theorists, list a slew of qualifiers that describe our affective bonds with media: 'delight, terror, geeky enthusiasm, mildly hypnotic euphoria, ugly feelings, and paranoid rage' $(2012,4)$. There are many recent examples that can serve to illustrate these affects, but one of the most intensely studied instances is that of Google Glass, a piece of wearable computing developed by tech giant Google. Hailed as a crowning achievement of the media technological industry, the glass, even before it had even become available to the larger public, was already associated with a case of so-called internet addiction. Google Glass is a head-mounted technological device developed in the quest for ubiquitous computing, acting as a mediator between its human wearer, the amassed informational assemblage of the internet, and material environment. The glass is operated through an inbuilt touchpad, or though natural language: the user can issue voice commands, activating various applications available on the glass's software platform.

While the glass was launched for retail in mid-2014, its price and availability ensured that it was available only to a select public. And less than a year after its launch, in January 2015, Google announced that it would cease manufacturing the device - Google Glass had become a media artefact after a short-lived stint on the media market. In the meantime, however, the glass became embroiled in a discourse of anxiety related to media use. In October 2014 news outlets started to report the case of a US Navy employee who was diagnosed and consequently sent to a rehabilitation centre to treat his Google Glass induced internet addiction, as well as several other behavioural addictions. A research paper co-authored by Yung, Eickhoff, Davis, Klam and Doan, titled 'Internet addiction disorder and problematic use of Google Glass ${ }^{\mathrm{TM}}$ in patient treated at a residential substance abuse treatment program' (2015), approaches the case from the point of view of its treatment, possible causes, and relation to other 'process' addictions. While the case is undeniably fascinating from a clinical point of view, the purpose of this paper is to examine the philosophical standing of technology within the discourses of addiction tied to Google Glass.

Media technologies invoke multiple binds of fear/fascination/necessity, and the discourse on Google Glass sharply illustrates the way in which these tensions are deployed as symbolic and material tools to manage attention in ways that are compatible with a capitalist imaginary of functionality. At the same time, the glass has been interestingly coined as a potential attention-enhancing tool, and has been successfully used as a classroom aid for children with ADHD and other focus-related difficulties. Google Glass is an example of technological 
media which are embroiled in a pharmacological discourse ${ }^{1}$ in the Derridean sense: they signify something that is both a poison and a cure, inextricably so - however, it is by no means unique in this respect. Yet, due to the interest it has garnered in news media, it is a productive starting point for a broader analysis of the nexus of attention, media, and ideas regarding the 'proper' way to engage with technology.

The arguments in this paper labour under the emblem of Martin Heidegger's distinction between proper and improper ways of approaching technology use (1977). Heidegger's inquiries into the nature of technology serve as a starting point that provides a basis for distinguishing between different ways of using technology. His distinction between proper and improper ways of using technology is echoed in much contemporary discourse on technology, especially technologies of communication (Turkle 2011; Carr 2010, 2014; Bauerlein 2008, 2011). In short, the proper/improper dichotomy is used to categorize not just types of technology, but also to hierarchize modes of being.

\section{Technogenesis and the Technical Individual}

Humans coevolve with technics: that is, humans emerge through their relationships with technics and vice-versa - this is an argument developed with media theorists as diverse as $\mathrm{N}$. Katherine Hayles (2012), Bernard Stiegler (1998) and Marshall McLuhan (1977). Stiegler and McLuhan see technics as an extension of 'man', and while their approaches and arguments are surely different, it is noteworthy that both theorists embed technics in the vocabulary of the lack and the supplement. Stiegler's humans needed technics in order to supplement an essential lack within their nature. McLuhan's man extends his bodily and psychical capacities through technics, but the extension always entails its flipside as well, the amputation $(1964,43)$. While McLuhan does not insist on this point too much, he makes it clear that the act of extension-amputation must be a dual operation in order to maintain a state of equilibrium within man. The possibility to extend some of man's capacities is conditional upon the autoamputation of other capacities. For example, the invention of the wheel, which extends the scale and speed and scope of movement comes with the function of walking losing some of its importance - being amputated (ibid., 42). Another example would be the loss of the tradition of letter writing (with all of its associated rules and rituals), which has been largely replaced by email.

The technical individual, in these works, is therefore characterized by a simultaneous sense of extension and loss. Not so in the work of N. Katherine Hayles, who sees the technical individual as a decidedly more productive figure, 'enmeshed in in networks of social, economics, and technological relations, some of which are human, some nonhuman' (2012, 13). It is not an essential lack that underlies technical individuality for Hayles, but rather an alternative understanding of embodiment, figured as part of extended cognition, in which 'human agency and thought are enmeshed within larger networks that extend beyond the desktop computer into the environment' $(2012,3)$. Both humans and technics are mutually embedded into cycles of 'coordinated transformations' (2012, 81). For Hayles, it seems,

\footnotetext{
${ }^{1}$ The notion of the pharmakon, in Jacques Derrida's work, expresses the double-bind several inseparable philosophical binaries such as poison/remedy, inside/outside, presence/absence, good/bad etc. A pharmacological discourse is one that cuts both ways, is ambivalent, and creates the very possibility for the two opposites to exist while being overlapping and inextricable.
} 
using technology is not a question of filling a lack, or replacing tools with their more advanced iterations, but an organic, dynamic assemblage containing both the human and technics.

The medical reading of media addiction, as illustrated by the case of the Google Glass addict, suggests that addicts consider technology as an extension of skills that make both their professional and personal lives more productive. The patient in Yung et al.'s research confessed that wearing the Google Glass allowed him to 'function at a high level' and 'increased his confidence with social situations' $(2015,59)$. While for the patient himself technology is a welcome extension of cognition, the medical discourse on the case figures technology as an amputation of human attention and cognitive abilities, since the removal of the glass caused the patient to display certain 'glitches': impaired short term memory, avoiding eye contact with the examiners, 'restricted' affect, loss of his train of thought (ibid.). Without trivializing either the researchers' observations or the patient's avowed symptoms, it is still possible to note that they are informed by a very particular conceptualization of human-technics interaction: one that seeks to maintain a very clear separation between the human user and technical artefacts.

However, if we are to frame the Google Glass addict as a technical individual embroiled in a process of technogenesis, the picture depicted by Yung et al. would look quite different. A rigorous biopolitical analysis of the case could certainly reveal the stakes of pathologizing media addiction. As a first step in this direction, it might be productive to focus on the idea of attention, which for Hayles, is an essential component of the technogenetic process.

\section{Deep Attention, Hyper-Attention and the Way We Think Today}

Attention, much like any other concept that has gained a foothold in both the sciences and the humanities, is much too fuzzy to be taken for granted. Philosophy, psychology and neuroscience are all known to have paid attention to attention, and have produced their own (often similar or related) models of it. In news coverage on media technologies and their potential effects on human capacities to "pay attention", its meaning can only be guessed at. What can be deduced is that the "attention" that is under threat in discourses of harmful media use, is the following: (1) it is material because it resides in the body; the source of attention is the human who is performing a task, using a piece of technology etc.; (2) attention, while voluntary, is easily stolen and distributed towards something other than its original goal; (3) attention is a scarce resource that must be managed carefully. The vernacular model of attention is based on the binary model of attentive subject - object of attention, in which the process of attentiveness passes from one to the other and back in a feedback loop.

Attention is also something that has carved itself deep enough into postindustrial capitalism to warrant a systemic approach of its own: the attention economy, where attention is scarce commodity with a high price. According to Tiziana Terranova (2004), the current iteration of the attention economy is also its first and original iteration. In her view, the capitalist model of attention economy emerged at the same time as digital media. The larval form of the attention economy seemed less harsh and demanding. Its main target was information, which was plentiful in the early stages of the development of the internet and other digital communication networks (Terranova 2004, 1). It seems that early digital economy was 
infused with a tacit kind of vitalism: information was seen as an artificial form of life, prone to proliferation. Digital media were thought to produce at the time (in the late 80s and early 90s) a new type of bios, a cybernetic ecosystem that followed a Darwinian trajectory of natural selection and evolution. The shift to a scarcity-oriented economy of attention put an end to this creative energy, leaving in its stead a 'tension between the previous, abundant, inventive bios of organic life and the new centrality accorded to the bios of a special organ, the brain, but one that is strangely deprived of its capacity for creation and innovation' (ibid., 2).

However, according to scholars such as N. Katherine Hayles, no model of attention is ever universal. Hayles' research suggests that modes of attention have shifted throughout history, and this shift is not merely cultural, but neurological as well. For Hayles, our ways of paying attention are not only a response to the media that we employ, but are also feeding into a structural change on a neurological level $(2012,3)$. Our brains and their capacities have been altered by the way in which we pay attention to (and therefore use) various media technologies. Hayles's example is that of 'older' analogue media, whose demands on human attention were significantly less intensive than that of their digital counterparts. Older media demanded 'deep attention', a way of concentrating on an object for long periods of time (Hayles 2007, 187). Hyper attention, on the other hand, is the type of attention allowed by our networked, digital present, she argues. The mode of engagement allowed by digital media is one that which requires 'high levels of stimulation, has a low tolerance for boredom, and operates through a rapid alternation between multiple streams of information' (Hayles 2012, 12). Attention is one of the key terms in understanding technogenesis, in Hayles' view, understood not as a cognitive ability or property, but as a process engaged in a feedback loop with the technical environment in which it operates (2007). That is, attention is both determined and determines technical innovation, and therefore the birth of 'new' media.

Hayles' arguments result from a serious commitment to literary and media studies and her tone is reflective rather than damnatory. While, like several other scholars and commentators who worry about the impact of media, she does not deny the significant changes on a social and cognitive level that have emerged with networked media, her approach is radically different from the media criticism of such writers as Nicholas Carr and Sherry Turkle. Carr argues that digital media is leading to the decline not only of traditional 'offline' sociality, but also of 'deep thinking' (2008). For Carr, digital media is unable to fulfil some fundamentally human need for intellectual 'vibrations', reverberating in some quiet space far removed from the constant buzz of the network (ibid.). Despite its benefits, the internet (the chief target of Carr's analysis) is very close to tarnishing something important not only in our intellect, but also 'in our selves . . . in our culture' (2008). Sherry Turkle's critique of digital media puts forward similar ideas, but with a more marked focus on the social rather than the individual. In Alone Together (2011) she cautions against the degradation that digital media (social media especially) wreak on the genuine, organic types of social interaction which used to be the norm in earlier times.

These examples point towards a trend that is quite widespread in lay discourse as well - a problematization of digital media in terms of how it affects the human, or (more generously) our shifting understanding of what it means to be human. Digital media, by opening a window to a different world, cause people to neglect their responsibilities to their selves, bodies and social bonds in their non-digital reality. Turkle and Carr do not pay any special attention to the relations that emerges between media and human, beyond an object/subject approach. The 'digital' and the 'real' seem to stay firmly separate in these accounts (a theoretical fallacy that is often called 'digital dualism'). Hayles, however, is careful to point 
out that human interactions with media are always embodied, taking the form of 'extended cognition, in which human agency and thought are enmeshed within larger networks that extend beyond the desktop computer into the environment' (2012, 3). For Hayles, the problem of the shift from deep attention to hyper attention is couched by her implicit claim that human-media interactions are processes of adaptation, of co-emergence and mutual construction (ibid., 81). Hyper attention is then the result of an attempt to fit within a constantly dynamic technical environment, a means of synergizing the human and the technical nonhuman, so as to fit the demands of a postindustrial capitalist system that constantly rearranges and repurposes objects and people (ibid., 101).

What of Google Glass then, if hyper attention is inevitable? Through a technogenetic lens, the case of the pathological Google Glass user becomes an instance of extremely successful adaptation to a specific technical environment. The Navy officer diagnosed with Google Glass addiction reported that the device helped him to become more productive and 'function at a high level by accessing detailed and complicated information quickly' (Yung et al. 2015, 59). The markers of his adaptation or coevolution with the medium were interpreted as symptoms of addiction, namely the physical reflex of touching his head as if to use the glass, even when not wearing it. By using the device for up to eighteen hours a day, however, the patient fashioned himself into a personally fulfilling version of a productive subject.

These technologically-inflected biopolitical meditations allow us to distinguish several ways in which the technology user (and therefore technology itself) can turn into a (medical) threat. On the one hand, technology is assumed to be imbued with autonomy and agency, and therefore with the power to act upon humans in 'improper' ways. On the other, the integrity of the subject is endangered: the flow of affect between technology and humans erodes the boundaries between human and nonhuman elements, and the subject faces the threat of contamination. So how is this threat dealt with? Gestures of medicalization are one possibility, and moral interventions are another. Medicalization, as Foucault discussed widely in his History of Sexuality (1978), is a means of social control, involving not only the demarcation between normal, pathological and deviant, but also taking hold of the body as an object of legitimate concern for instruments of power. Hardt and Negri $(2013,227)$ argue that moral interventions are actions that are assumed to be grounded in ethical or moral imperatives, and they give the example of extra-governmental organizations and NGOs, religious organizations and even the news media.

Moral interventions can also occur in the case of affective bonds with an improper (but not necessarily erotic) object of desire. Google Glass allows its user to interact with their material environment and beyond through fluxes of information transmitted through the glass. Currently, Google Glass can be used for face recognition, translation, connecting to the 'internet of things', medical self-surveillance and measuring and codifying one's environment (real-time weather check, measuring distances etc.). One recent research project uses the glass to develop a tool that would allow people on the autistic spectrum to 'read' other people's emotions. These applications of the Google Glass are decidedly valuable, they are productive engagements with technological assemblages. But often, the potential productivity of technology use is framed through a moral discourse oriented less towards simple engagement, and more towards a type of surveilled, controlled engagement.

This type of moral discourse is not limited to Google Glass, however. A similar kind of discourse can be observed on a micro-level in the case of productivity apps, small bits of software that can be installed on various media platforms (such as browsers, mobile operating systems), which limit or modulate the user's engagement with the medium in the name of 
'becoming more productive'. For example, Cold Turkey is a program that can block websites or applications for a set period of time, claiming to boost productivity by helping you to 'get in the zone' by 'completely removing tempting distractions (Logic 2015). Cold Turkey affects the entire computer, but there are many similar apps, add-ons and plugins that act only on a specific bit of the software: Leechblock for Firefox, StayFocusd for Chrome, etc. An app called The Productivity Owl takes the idea of the agency of the nonhuman even further: this Chrome extension consists in a cartoon owl that hovers around the browser, and closes any open tabs that are not work related.

The disciplinary objects of productivity apps are not extreme cases such as media addicts, but regular users who interact with digital technologies on a daily basis as part of their work or study. The simple act of interacting with a medium is underpinned by a negotiation of productivity and distraction, embroiled into certain disciplinary apparatuses: apparatuses that regulate which media content are eligible in order for the user to balance implicit norms of knowledge production. These negotiations are necessarily following in the footsteps of the pharmakon: they are part of the human user's entanglement with something that is at the same time poison and cure. Productivity and efficiency can often be framed as moral issues an idea that has been explored by economic theorists, philosophers - and it seems to be one of the pillars of capitalist exploitation as well. Productivity is managed on various institutional levels such as at school, but also on a smaller scale such as productivity apps as well. The existence and popularity of these apps, extensions and add-ins can be read to mean that productivity, as the opposite of 'distraction', is morally superior to it.

\section{The Materiality of Media Use}

In light of the previous section, the Google Glass addict's illness can be read as a disorder of attention, or a materialization of attentiveness that failed to be productive in the 'proper' way. While as mentioned earlier, the man believed that the glass made him better professionally and socially, his medical evaluation focused on the shortcomings of his performance of health and social adequacy. From a medical point of view, using Google Glass is a matter of adding or removing a technological artefact, and adapting the body and cognition to the demands of the medium. However, as several theorists including Hayles have argued, media are never singular. For Hayles, this is because media technologies produce an infinite mass array of cultural objects (2015), while for network theorists like Alexander Galloway, no media is ever self-contained and is imbricated into an assemblage of other media (2012, 31). Using media means plugging into vast assemblages that span across human and nonhuman elements. The intimate connection between human and machine is often characterized through concepts such as affect, modulations, intensities, flows and events. These concepts point towards a material kind of material performativity, a dynamic process of regulation and constraining that occurs between a human user and a technological assemblage.

Hayles sees attention as part and parcel of matter's emergence as well (2012, 103-104). She posits that materiality has an infinite potential for physical and symbolic attributes, allowing attention to zoom in on some of them. As such, she approaches materiality as a 'not a pregiven entity but rather a dynamic process that changes as the focus of attention shifts' (2012, 14). She does not clarify how attentional forms 'decide' which attributes to latch onto, which could cause some confusion over how subjective materiality really is. If attention "notices" a 
few characteristics out of an infinity of possibilities, then surely the materiality produced by one attentional form is likely to be radically different from that of another. And yet, materiality is mostly stable enough in order to allow observers to settle on a common perception of matter, or at least a common vocabulary. A rock materializes into a rock under the touch or gaze of most humans, after all. However, a few pages later, Hayles allows that

like humans, objects also have their embodiments, and their embodiments matter, no less than for humans. When objects acquire sensors and actuators, it is no exaggeration to say they have an umwelt, in the sense that they perceive the world, draw conclusions based on their perceptions, and act on those perceptions. $(2012,17)$

Attention, as a material process, depends not only on the subject's perceptual capacities, but also on what/how matter reveals itself through its process of materialization. Matter, for Hayles as well as for proponents of the new materialisms, is imbued with agency. This is especially noteworthy, considering that for Hayles the specificity of the medium is of prime importance. Reading and interacting with a digital medium, entering an assemblage with a digital medium, is fundamentally different than doing the same with a print medium, for example. Hayles argues that attention is a much neglected but essential part of this process. Materiality must not be confused with physicality, according to Hayles - while materiality is an emergent property of an assemblage, physicality, as already mentioned, is composed of an infinity of possible traits $(2012,91)$. Therefore, Hayles concludes, materiality emerges 'when attention fuses with physicality to identify and isolate some particular attribute (or attributes) of interest' - which actually makes materiality a human-technical hybrid (ibid.). Within this framework, materiality, attention and agency are mutually constitutive processes that inflect the way in which human-technics relations are discursively constructed.

This begs the question of where we can situate agency within the human-technical hybrid of media usage. After all, in the case of the Google Glass addict, the symptoms of addition can be read as a loss of agentic capabilities. If the addicted human does not have control over their affective bond to the technical artefact, then does it mean that agency is relegated to the machine? The medical reading of media addiction seems to point towards an understanding of materiality (both that of the media addict's body and the technical artefact), the constitution of attention, and agency. The device, seen as a supplement that rewires the subject's positioning within the structures of work and social life, is a source of dysfunction. Instead, through a materialist lens that considers the co-constructive relations between bodies and technics, it might be possible to take first steps towards a comprehensive analysis of human technics relationality that avoids the pitfalls of excessive pathologization.

\section{Conclusions}

This is a model of attention that can still work within the prescriptions of the attention economy. No matter how material, attention remains a limited resource involved in the circuits of postindustrial capitalism. But for the media addict, this tiny shift can have significant consequences. I am not suggesting that refiguring the media addict/media user through a materialist, entangled lens will overhaul the subject positions made available to her within the attention economy. However, seeing the media addict as a human-technology configuration or as a mode of human-machine co-existence can become an affirmative reading that counters some of the ways in which the medical discourse on attentional 
processes assigns negative meanings to certain ways of paying attention in the context of technology use.

Google Glass is yet another digital media device created with the purpose of channelling attention in proper ways, only to have it backfire according to some medical researchers. The moral of the story, according to Yung et al. (2015) at least, is that that all technologies can trouble proper performances of 'humanness', no matter how useful they were meant to be. But through a media theoretical reading, the anecdote of the glass addict might suggest that neither media, nor the human, nor their environment can be considered separately: they are all entangled, with a notion of embodied attention over them all.

As a direction for further research, the medical discourse on media addiction could lead into interesting directions if a gendered analysis is introduced into the mix as well. Feminist historians of science describe how the relationship between genders and technics has been a mutually reinforcing and hierarchizing one. Feminist science and technology studies (STS) scholars such as Sandra Harding (1986), Judy Wajcman (1991, 2000) and Wendy Faulkner (2001) have zeroed in on the various ways in which gender and technology can converge. Faulkner (2001) points towards two ways in which feminist STS scholars have approached the gender question in technology studies: gender in technology, and the gender of technology. The former regards the way in which gender and technology mutually embody, and materially shape each other (Faulkner 2001, 83). The other approach considers how particular technological artefacts are gendered as either masculine or feminine because of their proximity to, and predominant association with one gender or another. Historically, technology has been symbolically associated with masculinity, and 'cultural images and representations of technology converge with prevailing images of masculinity and power' (ibid., 79). However, as the example of the Google Glass may suggest, the association of masculinity and technics is increasingly complicated by the unstable discourses regarding the properness of media use.

As to the medium being the supplementation of man, McLuhan interestingly calls the use of the medium both amputation and extension of humans through technical form $(1964,11)$. Amputation is an interesting choice of words, not least because it conjures up echoes of the psychoanalytic notions of castration and phallic envy. In this sense, the autoamputation imposed by media use is symbolic of a profound loss, and perhaps even mourning of the media that came before the act of amputation - a mourning of traditional affective phenomena and modes of existence ${ }^{2}$. Media as amputation seems like a terribly masculine fear, in this sense. Women never took ownership of technology in the first place, if the canon of technology studies is to be believed. This presents us with an interesting quandary: if media are traditionally masculine (as per various histories and sociologies of technology), but at the same time a gesture of autoamputation and symbolic of an originary lack, then we must conclude that they are continuously exerting a process of feminization over those who would use them. The technical individual is not a man, it is the terror of the lack, projected onto an embodiment that is already considered to be missing a part. The Google Glass addict's reason for using the glass is the promise of supplementing 'natural' abilities, and the loss of the device is constructed as both a (technical) loss and a reappropriation of specifically and purely human sociality and cognitive functions.

Media are not simple, and neither are the processes through which they emerge; the meanings and uses attributed to them, their glitches and errors, or the relations into which they become

\footnotetext{
${ }^{2}$ Like Nicholas Carr's and Sherry Turkle' anxieties over the loss of traditional modes of social organization.
} 
entangled along with elements such as humans, economies, cultures, systems of knowledge etc. It is the relations that take shape between all these aspects that are crucial in understanding singular aspects of media-human relations, such as media addiction.

\section{References}

Barad, K. (2003) 'Posthumanist Performativity: Toward An Understanding Of How Matter Comes To Matter'. Signs 28 (3): 801-831

Bauerlein, M. (2008) The Dumbest Generation. New York, NY: Jeremy P. Tarcher/Penguin.

(2011) The Digital Divide. New York: Jeremy P. Tarcher/Penguin.

Carr, N. (2008) 'Is Google Making Us Stupid? What The Internet Is Doing To Our Brains'. The Atlantic. Available at http://www.theatlantic.com/magazine/archive/2008/07/is-google-making-usstupid/306868/. Accessed 7 December 2015.

(2015) The Glass Cage: Automation And Us. New York: W.W. Norton \& Company.

(2010) The Shallows. New York: W.W. Norton.

Logic, F. (2015) 'Get Cold Turkey' [online] Available at http://getcoldturkey.com/ . Accessed 17 December 2015.

Faulkner, W. (2001) 'The technology question in feminism: A view from feminist technology studies'. Women's Studies International Forum 24 (2):79-95.

Foucault, M. (1978) The History Of Sexuality. New York: Pantheon Books.

Fuller, M., and A. Goffey (2012) Evil Media. Cambridge, Massachusetts: The MIT Press.

Galloway, A. R. (2012) The Interface Effect. Cambridge, UK: Polity..

Harding, S. (1986) The Science Question in Feminism. Ithaca, NY: Cornell University.

Hardt, M., and A. Negri. (2013) 'Biopolitical Production'. In Biopolitics: A Reader, 1st ed., 215-236. Durham and London: Duke University Press.

Hayles, N. K. (2007) 'Hyper And Deep Attention: The Generational Divide In Cognitive Modes'. Profession 2007 (1): 187-199.

(2012) How We Think. Chicago: The University of Chicago Press.

Hayles, N. K., and J. Adema. (2015) 'Technogenesis And Media Specific Analysis:

N. Katherine Hayles'. Podcast [online] Culture Machine Live. Available at 
http://culturemachinepodcasts.podbean.com/e/technogenesis-and-mediaspecific-analysis-n-katherine-hayles/. Accessed 7 December 2015.

Hayward, E. (2008) 'More Lessons From A Starfish: Prefixial Flesh And Transspeciated Selves'. WSQ: Women's Studies Quarterly 36 (3-4): 64-85. doi:10.1353/wsq.0.0099.

Heidegger, M. (1977) The Question Concerning Technology, And Other Essays. New York: Harper \& Row.

McLuhan, M. (1964) Understanding Media: The Extensions Of Man. New York: McGraw-Hill.

Parikka, J. (2012) 'New Materialism as Media Theory: Medianatures and Dirty Matter', Communication and Critical/Cultural Studies 9(1): 95-100.

Parikka, J. and T. D. Sampson (2009) The Spam Book. Cresskill, N.J.: Hampton Press.

Peters, J.D. (1999) Speaking Into The Air. Chicago: University of Chicago Press.

Sampson, T. D. (2012) Virality: Contagion Theory in the Age of Networks. Minneapolis: University of Minnesota Press.

Stiegler, B. (1998) Technics And Time. Stanford, Calif.: Stanford University Press. (2012) 'Relational Ecology and the Digital Pharmakon' Culture Machine 13.

(2013) What Makes Life Worth Living: On Pharmacology. London: Polity Press.

Terranova, T. (2004) Network Culture. London: Pluto.

Turkle, S. (2011). Alone Together: Why We Expect More From Technology And Less From Each Other. New York: Basic Books.

Wajcman, J. (1991). Feminism confronts technology. University Park, PA:

Pennsylvania State University.

(2000). 'Reflections on Gender and Technology Studies: In What State is the Art?'. Social Studies of Science 39(30):447-464.

Yung, K., E. Eickhoff, D. L. Davis, W. P. Klam, and A. P. Doan (2015) 'Internet Addiction Disorder And Problematic Use Of Google Glass ${ }^{\mathrm{TM}}$ In Patient Treated At A Residential Substance Abuse Treatment Program'. Addictive Behaviors 41: 58-60.

Eva Zekany is a PhD Candidate in the Department of Gender Studies at the Central European University, Budapest. 
E-mail: Zekany_Eva@phd.ceu.edu 